\title{
Underground main pipeline behaviour under a travelling impulse in the form of a triangle
}

\author{
Barna Rakhmankulova ${ }^{1 *}$, Sayibdjan Mirzaev ${ }^{1}$, Rakhmatjon Khusainov $^{2}$, and Saparboy \\ Khusainov $^{3}$ \\ ${ }^{1}$ Tashkent institute of irrigation and agricultural mechanization engineers \\ ${ }^{2}$ Institute of Mechanics and Seismic Stability of Structures named after M.T.Urazbaev \\ ${ }^{3}$ Postgraduate student, Bauman Moscow State Technical University
}

\begin{abstract}
The article presents an analysis of the dynamic response of an underground main pipeline under the action of a longitudinal wave, propagating in soil along the pipe. It is assumed that the elastic pipe has a finite length. A linear viscoelastic model of the "pipe-soil" system interaction is considered. The influence of a pulse in the form of a triangle on the deformed state of an underground main pipeline is investigated. The article presents a comparative analysis of the results obtained for some values of the coefficients of elastic and viscous interaction, the propagation velocity, and the duration of the pulse. In the case of elastic interaction of the "pipe-soil" system, the reflection of the wave propagating in the underground pipeline on the boundaries of the pipeline when it coincides with the wave propagating in the soil leads to an increase in the maximum deformation of the underground pipeline, the value of deformation can double. The viscosity coefficient of interaction at the pipe-soil system contact leads to the wave front attenuation in the underground pipeline. For soils with the coefficient of viscous interaction higher than $100 \mathrm{kN} \cdot \mathrm{s} / \mathrm{m}^{2}$, this leads to complete attenuation of the bursts at the wave front in the pipeline. The influence of the wave propagation in soil on the deformation values at the wave front was also studied.
\end{abstract}

\section{Introduction}

Underground pipelines are a key component of critical life support systems such as water supply, gas and liquid fuels, sewerage, electricity, telecommunications. The interaction with the soil structure caused by seismic waves has an important effect on the pipeline behaviour, and the integration across the entire pipeline network affects the performance of the entire system $[1,2]$.

The exceptional damage caused by the 1985 Michoacán (Mexico) earthquake prompted researchers to develop sophisticated tools for assessing ground motion in the Michoacán Valley (Mexico City) during earthquakes along the Pacific coast, including important effects observed in the city. These tools have helped to better understand how earthquakes affect buildings and other structures (including pipeline systems). The most notable case of pipeline damage, resulting from the 1985 seismic event, is extensive damage to Mexico

\footnotetext{
*Corresponding author: smirzaev@yandex.ru
} 
City's water supply system, leaving almost 3.5 million people without fresh water; the water supply interruptions lasted for two months.

Surface waves can be more destructive to buried pipelines than body waves, creating large soil deformation caused by their low phase velocity. Serious damage to underground pipelines caused by the effect of surface wave propagation was observed during the 1985 Michoacán earthquake in Mexico City [3]. Analysis of the soil structure interaction with surface waves propagating along underground pipelines is of practical importance for assessing pipe damage and the response of a life support system. Underground pipelines can be divided into continuous pipelines (for example, welded steel pipelines) and segmented pipelines (precast concrete cylinders and cast iron pipelines). Observations of previous earthquakes show that the axial thrust in joints is the main type of destruction of segmented pipelines [2-3].

In recent decades, much attention was paid to the impact of wave propagation on segmented underground pipelines. In [2-6], various models were proposed to analyze the interaction of segmented pipelines during wave propagation.

Damage to underground pipelines during an earthquake could be caused by several different types of hazards: permanent soil deformation (landslides, liquefaction and seismic settlement) and wave propagation effect. The latter is characterized by transient deformation and ground curvature caused by the travelling wave effect. T.R. Rashidov and N.M proposed a simple procedure taking into account one travelling wave with an undamped (travelling) waveform. Newmark [7 - 8] to analyze the wave propagation. According to T.R.Rashidov's statement, the static theory was first considered by R.M. Mukurdumov [9] and then given in the monograph by Sh.G. Napetvaridze [10], where he has proposed that during wave propagation along the pipeline, the pipe and the soil move in the same way. N.M. Newmark later proposed a similar assumption that the underground pipeline strictly follows the soil movement, called a static theory. Therefore, the maximum axial deformation of the pipe is the same as the maximum axial deformation of soil.

However, the above procedures consider infinite pipe lengths and therefore do not consider their effective length and construction work (constraint conditions). In [11], analytical relationships were developed for a pipe of finite length subjected to various combinations of boundary conditions (i.e., free end, fixed or elastic end) for pipelines of different lengths. In 1962, T.R. Rashidov proposed a differential equation for an underground pipeline, which became the basis of the T.R. Rashidov's dynamic theory [7, 11]. G. De Martino et al. [12] and V. Corrado et al. [13] developed models of the pipe-soil interaction, taking into account the finite length of the pipeline. Assuming a linear elastic model of soil motion and ignoring the slip at the pipe-soil contact interface, the model analyzes the dynamic behaviour of a finite-length pipeline taking into account the boundary conditions at the ends. It was assumed that the pipeline was continuous; that is, any fluctuations between the characteristics (parameters) of the pipeline and its joints were considered insignificant. A.A. Ilyushin and T.R. Rashidov [2] proposed a viscoelastoplastic model of the underground structure interaction with the soil.

As shown in $[13,24]$, for pipelines with a free end, the results obtained agree with the values obtained using the above models for long pipelines only, while for short lengths, the maximum deformation of the pipeline is significantly less. For pipelines with a fixed end, ignoring the inertia of the pipeline and considering the infinite length of the pipeline, axial deformation is reduced, especially for short pipes.

The effect of the coefficients of elasticity, viscosity and plasticity of the pipeline interaction with soil on the stress-strain state of an underground pipeline is studied in detail in $[21-25]$. 
Since there are no generally accepted methods for predicting the actual propagation of seismic waves, we, therefore, consider the seismic action in the form of a triangular impulse. The soil motion parallel to the pipe can be written as

$$
u_{g}=\left\{\begin{array}{c}
\frac{4 A}{T} \cdot\left(t-\frac{x}{C_{p}}\right), \quad 0 \leq t-\frac{x}{C_{p}} \leq \frac{T}{4} \\
2 A-\frac{4 A}{T} \cdot\left(t-\frac{x}{C_{p}}\right), \quad \frac{T}{4} \leq t-\frac{x}{C_{p}} \leq \frac{T}{2} \\
0, \quad \frac{T}{2}<t-\frac{x}{C_{p}} \text { and } t-\frac{x}{C_{p}}<0
\end{array}\right.
$$

where $A$ is the amplitude of the ground motion; $T / 2$ is the duration of the pulse; $C_{p}$ is the "apparent velocity" of wave propagation (hereinafter, this term will denote the wave propagation velocity in soil). The "apparent velocity" of wave propagation in the soil can be large due to the angle of incidence of the wave to the pipeline axis or due to flexible pipeline joints.

The soil motion can be written in terms of deformations (see Figure 2), then function (1) has the form

$$
\varepsilon_{g}=\left\{\begin{array}{cc}
-\frac{4 A}{T C_{p}}, & 0 \leq t-\frac{x}{C_{p}} \leq \frac{T}{4} \\
\frac{4 A}{T C_{p}}, & \frac{T}{4} \leq t-\frac{x}{C_{p}} \leq \frac{T}{2} \\
0, & \frac{T}{2}<t-\frac{x}{C_{p}} \text { and } t-\frac{x}{C_{p}}<0
\end{array}\right.
$$

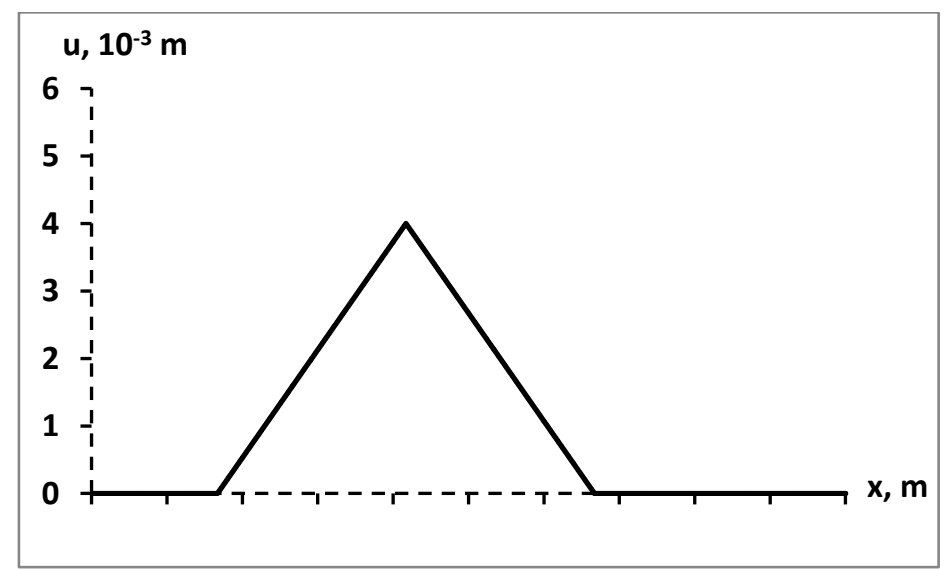

Fig. 1. Ground motion in the form of a travelling impulse as a triangle 


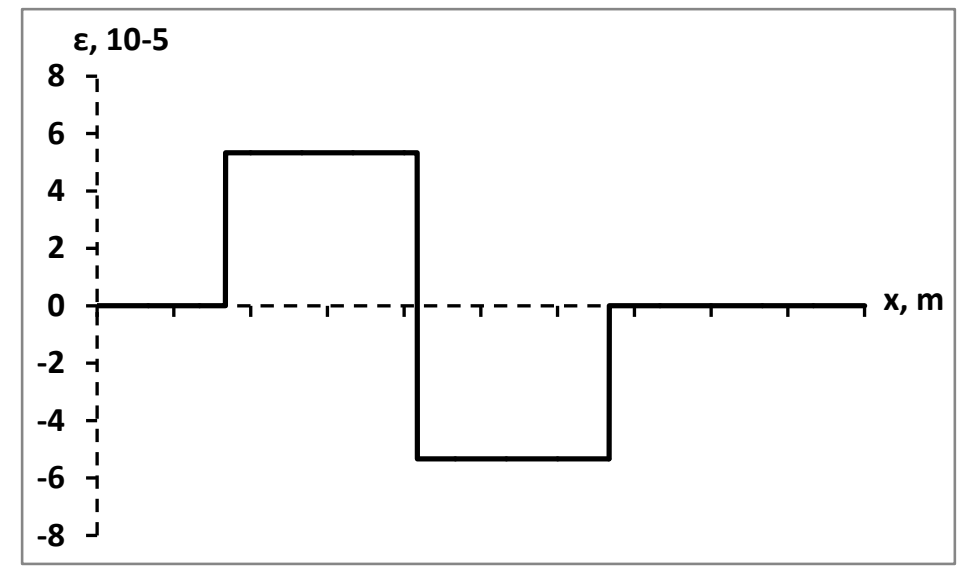

Fig. 2. Ground motion in terms of deformation

A wave in the ground is presented in the form of an impulse as a triangle (1), and then the deformation of the soil particles in the wave will change according to a step function (2). Therefore, at the wave front, the soil displacement is zero, and the particle velocity has a jump.

In [3], T.D. O'Rourke et al. concluded that $C_{p}$ is always greater than the propagation velocity $C_{s}$ of shear waves $(S)$ in the surface layers of soil and is $C_{s}=(G / \rho)^{1 / 2}$, where $G$ and $\rho$ are the tangential modulus of elasticity and the soil density, respectively. They also proposed a method for determining the apparent velocity, obtaining the value of $C_{p}=$ from $2.1 \mathrm{~km} / \mathrm{s}$ to $3.76 \mathrm{~km} / \mathrm{s}$ for the 1971 earthquake in San Fernando and 1979 in the Imperial Valley, respectively. The Committee on Gas and Liquid Fuel Resources considers these values inappropriate for analysis [14] because they ignore the waveform changes from one point to another [15]. Therefore, in [16] G. Manolis et al. proposed the values of $C_{p}$ in the range from 1.2 to $3.0 C_{s}$.

Statement of the problem. Let us consider the problem of longitudinal vibration of an underground main pipeline under linear viscoelastic interaction at the contact with soil, at three types of fastening $[22,25]$.

$$
m_{p} \cdot \frac{\partial^{2} u}{\partial t^{2}}-E \cdot F \cdot \frac{\partial^{2} u}{\partial x^{2}}+\pi \cdot D \cdot \frac{\mu}{H} \cdot\left(\frac{\partial u}{\partial t}-\frac{\partial u_{g}}{\partial t}\right)+\pi \cdot D \cdot k_{x} \cdot\left(u-u_{g}\right)=0
$$

here $m_{p}$ is the mass per unit length of the pipeline; $E$ is Young's modulus of the pipe material; $F$ is the cross-sectional area of the underground pipeline; $k_{x}$ is coefficient of elastic interaction of the "pipe - soil" system [17]; $\mu$ is the viscosity coefficient of the "pipe - soil" system interaction, that is, the resistance of the equivalent velocity of the "pipe - soil" system interaction; $H$ is laying depth; $D$ is outer diameter of the underground pipeline; $u(x, t)$ - absolute displacement in the section $x$ of the underground pipeline at the time $t ; u_{g}(x, t)$ is soil displacement corresponding to the section $x$ of the underground pipeline at the time $t$. 
1. If the constraints at both ends of the pipeline are such that they prevent all relative displacements between the structure at the ends of the pipeline (wells, pumping stations or in points of sharp turns in underground pipes) and the pipe (with fixed ends), then we assume that these ends are fixed to the ground, and obtain

$$
u=u_{g}, \quad \text { at } \quad x=0, x=L, t>0
$$

2. If the constraints at the ends of the pipeline are such that they can provide zero deformation (free ends), then the normal force is constant at $x=0$ and $x=L$, therefore

$$
\frac{\partial u}{\partial x}=0, \quad \text { at } \quad x=0, x=L, t>0 .
$$

3. If the underground pipeline is pliantly fixed at the ends, then we take the boundary conditions in the following form

$$
\begin{aligned}
& E F \frac{\partial u}{\partial x}=k_{N 1}\left(u-u_{g}\right), \quad \text { at } x=0, t>0, \\
& E F \frac{\partial u}{\partial x}=-k_{N 2}\left(u-u_{g}\right), \text { at } x=L, t>0,
\end{aligned}
$$

where $k_{N 1}, k_{N 2}$ - are the coefficients of fastening compliance at the left and right ends of the underground pipeline.

Initial conditions are zero

$$
u=0 \text { and } \frac{\partial u}{\partial t}=0, \quad \text { at } t=0, x>0
$$

Steel pipe characteristics are modulus of elasticity - $E=2.1 \cdot 10^{11} \mathrm{~N} / \mathrm{m}^{2}$, outer diameter$D=0.61 \mathrm{~m}$; thickness $-s=0.01 \mathrm{~m}$; mass per unit length ${ }_{-} m_{p}=141.1 \mathrm{~kg} / \mathrm{m}$, $k_{N 1}=k_{N 2}=29 \cdot 10^{4} \mathrm{kN} / \mathrm{m}$.

Soil characteristics are elastic interaction coefficient $-k_{x}=0.5 \cdot 10^{4} \mathrm{kN} / \mathrm{m}^{3}$; viscous interaction coefficient $-\mu=100 \mathrm{kN} / \mathrm{m}^{2}$; wave propagation $-C_{p}=2500 \mathrm{~m} / \mathrm{s}$; harmonic wave period $-T=0.2 \mathrm{~s}$; wave amplitude $-A=0.004 \mathrm{~m}$.

\section{Materials and Methods}

In [18] the methods of Crank-Nicholson, McCormack and Courant-Friedrich-Lewy (explicit scheme) are compared, and the accuracy of the explicit scheme relative to other methods when solving discontinuous problems of underground pipelines vibrations is shown. In that study, the problem is solved by the finite difference method in an explicit scheme. Careful numerical calculations were performed to prevent unwanted vibrations near the discontinuity (wave front deformation) [19]. 
The wave in the soil is represented as a sine, 0and then the ground particles velocity in the wave will change as a cosine. Therefore, at the wave front, the soil displacement is zero, and the particle velocity has a jump. Real records of strong ground motion show that movement, velocity, and acceleration of soil particles at the wave front have no discontinuity [20]. This is a disadvantage of presenting a sine wave in the ground. To get results closer to reality, it would be reasonable to use real earthquake records. There are several studies on the effects of stationary waves on an underground pipeline. In this regard, we will consider the effect of the non-stationarity of processes and the transfer to a stationary regime.

The wave propagation velocity in a steel pipeline is assumed $5120 \mathrm{~m} / \mathrm{s}$, and in the ground, this velocity depends on the soil type. Let us assume that a wave in the ground moves at a velocity of $2500 \mathrm{~m} / \mathrm{s}$.

Consider the equation of motion (3), initial conditions (7) and one of the boundary conditions (4), (5) and (6). Ground motion is given as a triangular impulse (see Figure 1).

The problem is solved using an explicit finite-difference scheme, with the choice of the ratio of steps in coordinate and time in the form $\Delta x / \Delta t=a$, where $a=\sqrt{E \cdot F / m_{p}}$ is the wave propagation velocity in the pipeline. The calculations were performed at $\Delta x=0.1 \mathrm{~m}$.

\section{Results and Discussion}

Soil deformation in the form of (2) at three points has discontinuities of the first kind; when these deformation discontinuities pass through the ends of the pipeline, three discontinuous fronts propagate in the pipeline. The value of deformation at the front with a rigidly fixed pipeline is approximately equal to half the value of the jump in soil deformation. Three deformation wave fronts propagate with the full transition of the pulse through the left end of the underground pipeline. To analyze these fronts, we indicate them as the leading, middle and trailing edges of the pulse, respectively. At the middle edge of the pulse, the deformation is twice as large as at the leading and trailing edges of the pulse. When the middle front is reflected from the right fixed end, as shown in Figure 3 at $t=0.32 \mathrm{~s}$, the wave is superimposed on the wave moving in parallel with the soil deformation pulse.

The damping of the leading edge with distance for the values of the viscous interaction $\mu=0,1,4,10 \mathrm{kN} \cdot \mathrm{s} / \mathrm{m}^{2}$ is shown in Figure 4. Hence, it is seen that at large values of the viscosity coefficient of interaction, the superposition of waves can be ignored due to the deformation attenuation at the fronts.

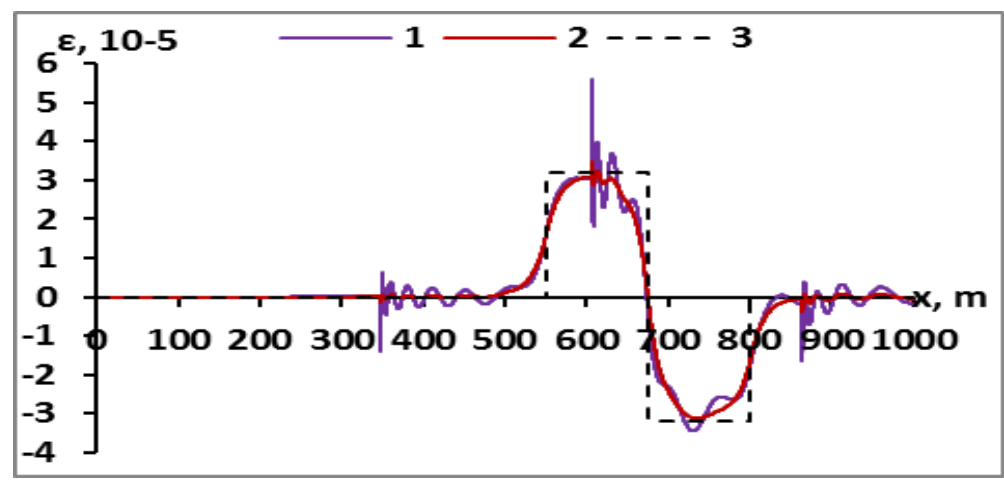

Fig. 3. Change of deformation along the coordinate at $t=0.32 \mathrm{~s}: 1-\mu=0 \mathrm{kN} \cdot \mathrm{s} / \mathrm{m}^{2} ; 2$ $\mu=1 \mathrm{kN} \cdot s / m^{2} ; 3-$ in soil $\left(T=0.2 s, C_{p}=2500 \mathrm{~m} / \mathrm{s}\right)$ 


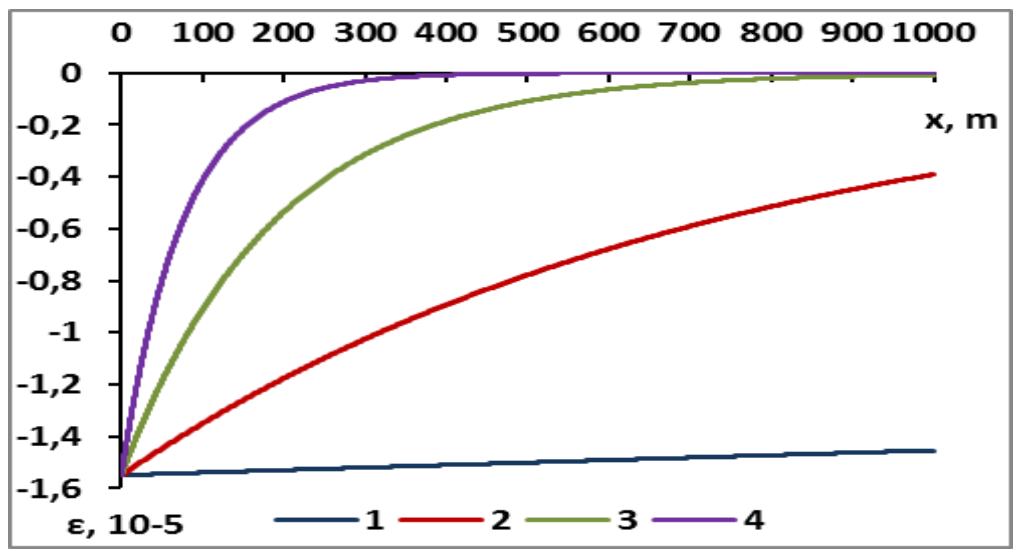

Fig. 4. Change of the underground pipeline deformation at the wave front along the coordinate.

$1-\mu=0 \mathrm{kN} \cdot \mathrm{s} / \mathrm{m}^{2} ; 2-\mu=1 \mathrm{kN} \cdot \mathrm{s} / \mathrm{m}^{2} ; 3-\mu=4 \mathrm{kN} \cdot \mathrm{s} / \mathrm{m}^{2} ; 4$

$\mu=10 \mathrm{kN} \cdot \mathrm{s} / \mathrm{m}^{2} \cdot\left(T=0.2 \mathrm{~s}, C_{p}=2500 \mathrm{~m} / \mathrm{s}\right)$

The velocity of wave propagation in soil affects the maximum deformation values and the wavelength of the deformation pulse. As for the ground motion, it affects only the pulse waveleng the (see Figure 5a). An increase in the velocity of wave propagation in the soil leads to an increase in displacement in the pipeline and decreased deformation (see Figure $5)$.

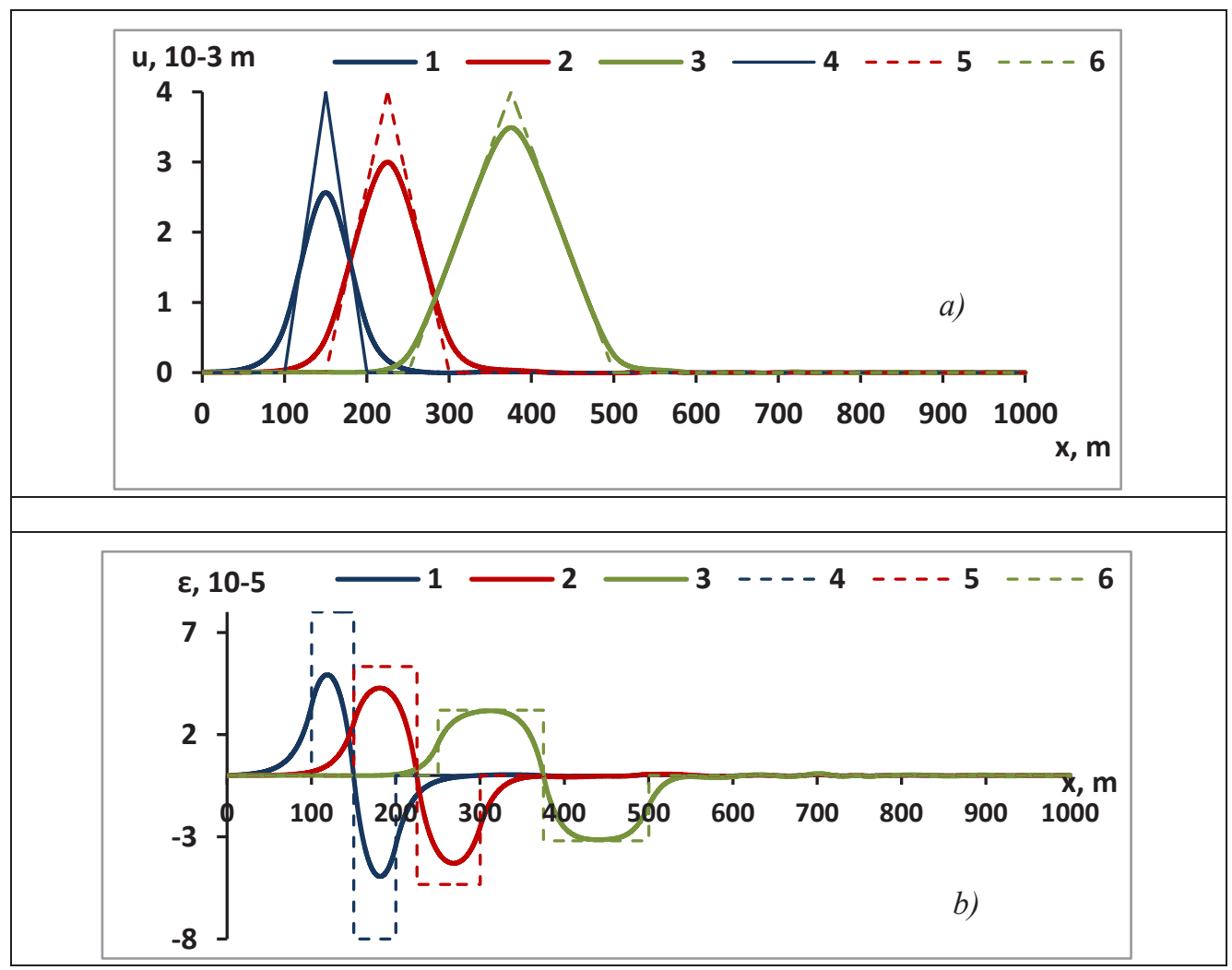


Fig. 5. Change in displacement (a) and deformation (b) along the coordinate when both ends of the underground pipeline are freely fixed: 1 is wave in the pipe at $C_{p}=1000 \mathrm{~m} / \mathrm{s} ; 2$ is wave in the pipe at $C_{p}=1500 \mathrm{~m} / \mathrm{s} ; 3$ is wave in the pipe at $C_{p}=2500 \mathrm{~m} / \mathrm{s} ; 4$ is wave in soil at $C_{p}=1000 \mathrm{~m} / \mathrm{s} ; 5$ is wave in soil at $C_{p}=1500 \mathrm{~m} / \mathrm{s} ; 6$ is wave in soil at $C_{p}=2500 \mathrm{~m} / \mathrm{s}$.

At small values of the impulse duration, the elastic interaction coefficient significantly affects the maximum value of displacement (see Fig. 6 (a)) and deformation (see Fig. 6 (b)) in the pipeline.
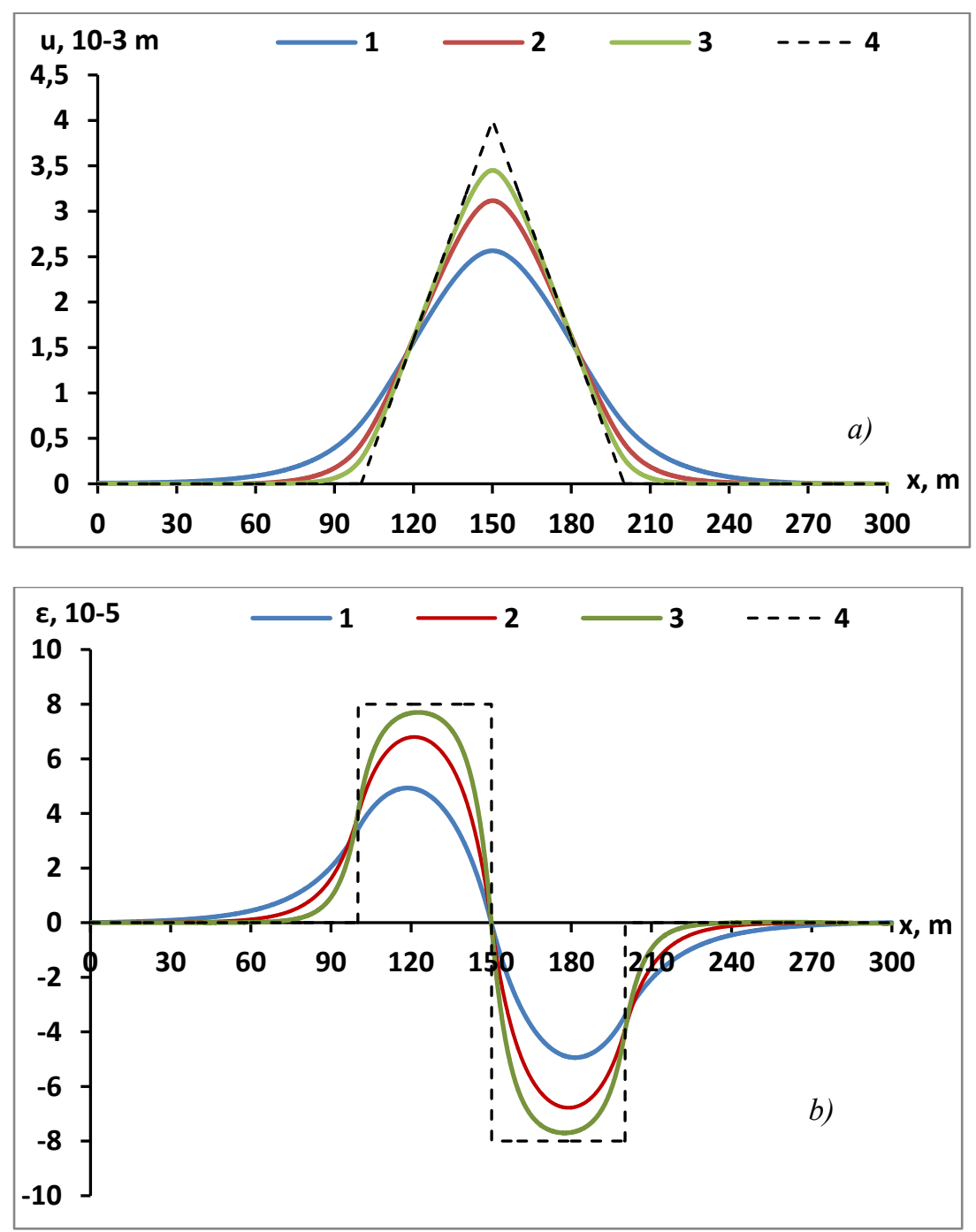

Fig. 6. Change in displacement (a) and deformation (b) along coordinate: 1 is $k_{x}=0.5 \cdot 10^{4} \mathrm{kN} / \mathrm{m}^{3}$; 2 is $k_{x}=1.5 \cdot 10^{4} \mathrm{kN} / \mathrm{m}^{3} ; 3$ is $k_{x}=4 \cdot 10^{4} \mathrm{kN} / \mathrm{m}^{3} ; 4$ is wave in soil.

At large values of the impulse duration in the form of a triangle, the maximum value of the pipeline displacement approaches the maximum value of the displacement in soil, but the maximum deformation values are not affected (see Figure 7). 

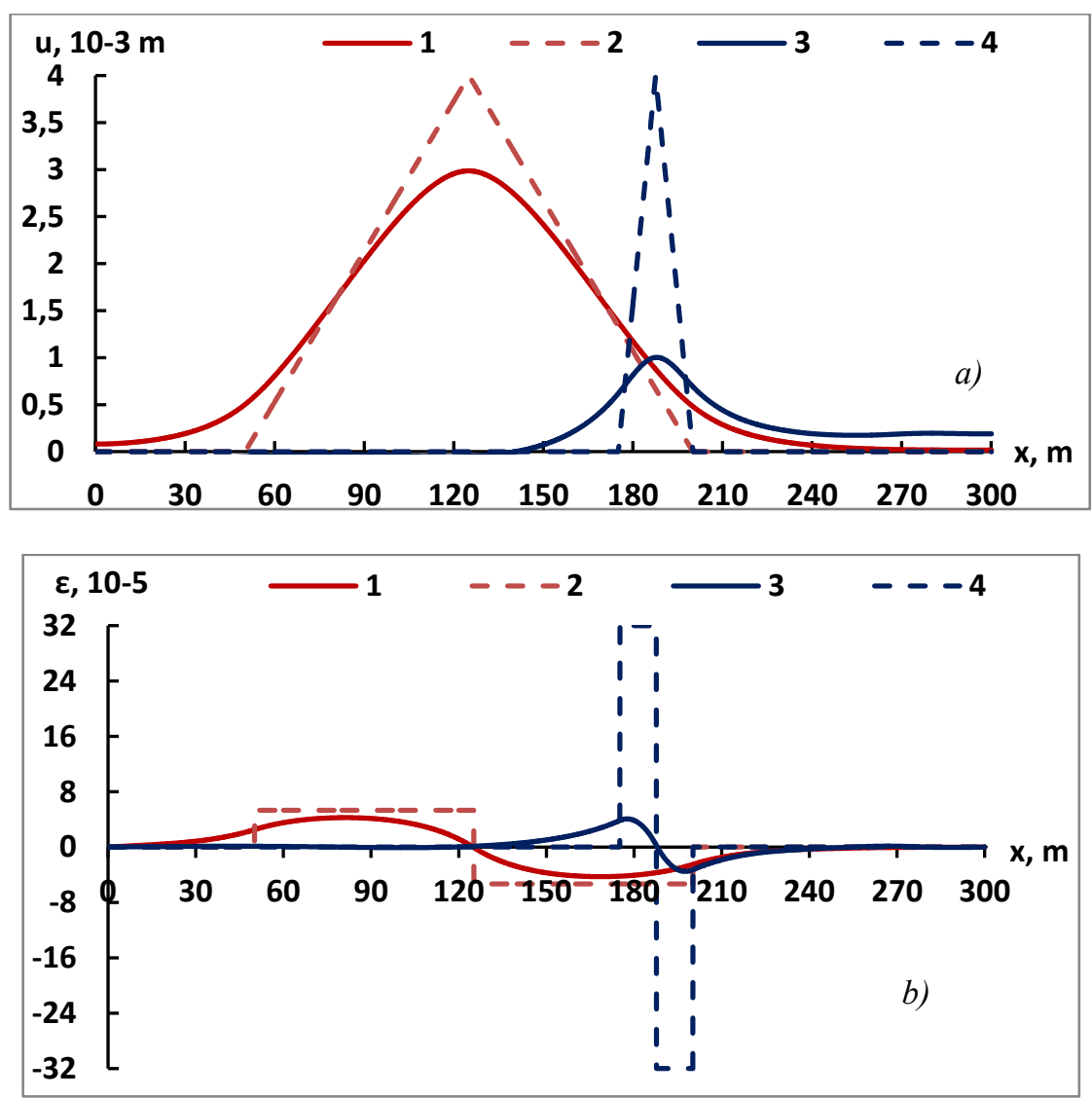

Fig. 7. Change in displacement (a) and deformation (b) along coordinate: 1 is wave in the pipeline $T=0.3 s ; 2$ is wave in soil. $T=0.3 s ; 3$ is wave in the pipeline $T=0.5 s ; 4$ is wave in soil. $T=0.5 s ; k_{x}=0.5 \cdot 10^{4} k N / m^{3}$.

An increase in the pulse duration leads to an increase in displacement in the buried pipeline, but the maximum deformation value almost does not change. The behaviour of an underground pipeline under the seismic action in the form of an impulse as a triangle differs from the action of a half-wave sine impulse, given in [21].

The wave propagating along the pipeline embedded in any type of soil attenuates with time and distance. This can be explained by the loss of energy into the soil surrounding the pipeline. Considering the loss of energy, it is possible to get rid of the bursts appearing at the wave front in the pipeline; this is confirmed by the results presented in Fig. 4.

\section{Conclusions}

The superposition of the reflected wave at the boundaries of the pipeline with the propagating wave in soil leads to an increase in the maximum deformation of the underground pipeline. Under elastic interaction, this value can increase twice.

The wave propagation velocity in the soil does not affect the deformation value at the wave front.

The influence of the viscosity coefficient of interaction on the deformed state of an underground pipeline was studied. 
The problem was solved for the case when the ground motion is specified in the form of a travelling impulse as a triangle. The graphs were plotted, and the analysis of the results was presented. The attenuation of the wave front in underground pipeline at large values of the viscosity coefficient of interaction with soil was shown.

The results of the numerical solution of the differential equation of the main pipeline longitudinal motion were presented. Ground motion was specified as a triangular impulse. Graphs were plotted, and the analysis of the results was made.

The viscosity coefficient of interaction at the pipe-soil system contact leads to attenuation of the wave front in the underground pipeline. For soils with the viscosity coefficient of interaction higher than $100 \mathrm{kN} \cdot \mathrm{s} / \mathrm{m}^{2}$, this leads to complete attenuation of the bursts at the wavefront in the pipeline.

\section{References}

1. O'Rourke T.D., Geohazards and large geographically distributed systems. Geotechnique; 60(7), pp. 503-543, (2010).

2. Rashidov T., Dynamic theory of seismic stability of complex systems of underground structures, Tashkent: Fan, 180 p., (1973).

3. O'Rourke M.J. and Liu X., Response of buried pipelines subject to earthquake effects, MCEER Monograph 3, Multidisciplinary Center for Earthquake Engineering Research, University at Buffalo, Buffalo, NY, USA, (1999).

4. Iwamoto T., Wakai N., Yamaji T., Observation of dynamic behavior of ductile iron pipelines during earthquakes, In: Proceedings of the 8th World Conference on Earthquake Engineering, VII. San Francisco, USA, pp. 231-238, (1984).

5. O'Rourke T.D., Wang Y., Shi P., Advances in lifeline earthquake engineering, In: Proceedings of the 13th World Conference on Earthquake Engineering, Vancouver, Canada, 5003, (2004).

6. Wang LRL., Some aspects of seismic resistant design of buried pipelines. In: Lifeline earthquake engineering: buried pipelines, seismic risk, and instrumentation (PVP-34). American Society of Mechanical Engineers, pp. 117-131, (1979).

7. Rashidov T., Differential equation of vibrations of an underground pipeline during an earthquake, Tashkent, Reports of the Academy of Sciences of Uzbekistan, 9, pp. 1012, (1962).

8. Newmark N.M., Problems in wave propagation in soil and rocks, In Proceedings of the International Symposium on Wave Propagation and Dynamic Properties of Earth Materials, University of New Mexico Press, pp. 7-26, (1967).

9. Mukurdumov R.M., Seismic resistance of underground pipelines. Tashkent. AS UzR, (1953).

10. Napetvaridze Sh.G. Seismic resistance of hydro-technical structures. M., Gosstroyizdat, p. 216, (1959).

11. T. Rashidov, Calculation of underground pipelines of finite length under the action of a short-term seismic load, Tashkent, Reports of the AS UzSSR, 4, pp. 13-16, (1963).

12. De Martino G., D'Acunto B., Fontana N., and Giugni M., Dynamic response of continuous buried pipes in seismic areas, in ASCE Pipelines Conference, (2006).

13. Corrado V., D'Acunto B., Fontana N., and Giugni M., Inertial Effects on Finite Length Pipe Seismic Response, MPE, p. 14, (2012).

14. American Society of Civil Engineers, Seismic Response of Buried Pipes and Structural Components, Committee on Seismic Analysis, New York, NY, USA, (1983). 
15. Mavridis G. and Pitilakis K., Axial and transverse seismic analysis of buried pipelines, In Pro-ceedings of the 11th World Conference on Earthquake Engineering, Acapulco, Mexico, (1996).

16. Manolis G., Pitilakis K., Telepoulidis P., and Mavridis G. A., hierarchy of numerical models for SSI analysis of buried pipelines, Transactions on The Built Environment, 14, (1995).

17. Ilyushin A.A., Rashidov T., On the action of a seismic wave on underground pipelines, Tashkent, Izvestia, ser. thechnical sciences, pp.37-42, (1971).

18. Corrado V., D'Acunto B., Fontana N., and Giugni M., Estimation of dynamic strains in finite end-constrained pipes in seismic areas, Mathematical and Computer Modelling, 49 (3-4). pp. 789-797, (2009).

19. Nikiforovsky V.S., Shemyakin E.I., Dynamic destruction of solids. Novosibirsk: Nauka, p. 272, (1979).

20. Anil K. Chopra., Dynamics of structures, Theory and Applications to Earthquake Engineering. Fourth Edition, Prentice Hall, p. 794, (2012).

21. Khusainov R.B., On the need to account for the wave entrainment of energy in the problems of calculating underground main pipelines, Problems of Mechanics, 4, pp.107-111, (2018).

22. Khusainov R.B., Longitudinal Deformation Wave in Buried Pipeline Subject to Viscoelastic Interaction with Soil, Soil Mechanics and Foundation Engineering, Springer, 56, pp. 420-426, (2020).

23. Khusainov R.B., Seismodynamics of Underground Pipelines during Visco-ElasticPlastic Interaction with Soil, IJARSET, 7(1), pp. 12468-12474, (2020).

24. Yusupov M., Shadmanova G., Rakhmankulova B., Ziyaeva Sh., and Umarov F., Numerical simulation of vehicle dynamics problems, Journal of Critical reviews, pp. 1815-1821, DOI:10.31838/jcr.0715.248, (2020).

25. Mirzaev S., Kholmatova I., Yusupov M., and Kubyashev K., International Conference "Construction Mechanics, Hydraulics and Water Resources Engineering" (CONMECHYDRO-2020), (2020). 